\title{
Assessing the Value Created in a Social Learning Space Intervention: Four Vignettes of Parasport Coaches
}

\author{
Tiago Duarte, Diane M. Culver, and Kyle Paquette \\ University of Ottawa
}

\begin{abstract}
In this paper, the authors reflect on the current literature and the evolution of coach communities of practice and how the coach development area has embraced Wenger-Trayner's social learning theory. Studies examining parasport coach development interventions, specifically those using a landscape of practice approach, are lacking. This paper is the third in a series about increasing learning capability in the wheelchair curling landscape. The authors utilized a collaborative approach to assess the learning value created through a 13-month social learning intervention. Four composite vignettes based on the coaches' pathways and residency within the landscape were created from the data generated and analyzed using the value creation framework. The vignettes illustrate the many dimensions of learning values experienced by the coaches. This paper advances the literature surrounding social learning theory by providing examples of the novel concept of different dimensions of learning value. Applied implications are included.
\end{abstract}

Keywords: coach development, disability sport, landscape of practice

Wenger's social learning theory (Lave \& Wenger, 1991; Wenger, 1998) has gained notable attention in sport coaching research (e.g., Cassidy \& Rossi, 2006; Stoszkowski \& Collins, 2012). The theory started with the concepts of legitimate peripheral participation and situated learning (Lave \& Wenger, 1991). These concepts were developed through the study of various models of apprenticeship, in which apprentices gain experience through their interactions with those who are further advanced in the particular domain. In sport, newcomer coaches at the periphery of a context develop as they engage with other coaches and assistant coaches who are closer to the core of the community (Cassidy \& Rossi, 2006). For those studying coach development, this notion was very intuitive, since a body of research has found that coaches cherish the learning acquired during their previous athletic experiences, both as athletes and as assistant coaches (e.g., Erickson, Côté, \& Fraser-Thomas, 2007; Rynne, 2014). An early evolution of the theory saw the development of the concept of communities of practice (CoPs). Wenger (1998) defined CoPs as a group of people who share interests and interact on an ongoing basis to deepen their knowledge in an area they care about (Wenger, McDermott, \& Snyder, 2002).

Within coach development research, some CoPs have been initiated by leading members of a community, such as coaches and sport directors (Callary, 2013; Culver, Trudel, \& Werthner, 2009), while other CoPs were developed by members outside of the community (e.g., researchers and coach educators), often as pedagogical interventions. These pedagogical interventions included compulsory undergraduate CoPs (Stoszkowski \& Collins, 2017), postgraduate program CoPs (Jones, Morgan, \& Harris, 2012; Vinson, Cale, Lasota, Huckle, Faulkner, \& Jones, 2019), and voluntary participation CoPs (Bertram, Culver, \& Gilbert, 2016; Garner \& Hill, 2017). The most notable outcomes reported by these

The authors are with the School of Human Kinetics, University of Ottawa, Ottawa, Ontario, Canada. Culver (dculver@uottawa.ca) is corresponding author. groups of researchers included increases of intrapersonal knowledge (Garner \& Hill, 2017; Stoszkowski \& Collins, 2017), increases of interpersonal knowledge (Araya, Bennie, \& O'Connor, 2015; Garner \& Hill, 2017), and convergence of practice and theory (e.g., Jones et al., 2012; Stoszkowski, Collins, \& Olsson, 2017). Among the studies that looked retrospectively at cases that resembled CoPs, researchers found an improvement in the levels of collaboration and trust among participants (Callary, 2013; Culver et al., 2009).

As the social learning theory developed, the theorists introduced the concept of a landscape of practice, defined as the boundaries and interconnections of multiple CoPs and networks (Wenger-Trayner \& Wenger-Trayner, 2015). With this use of the metaphor of landscapes of practice, at least two movements occurred: zooming out and zooming in. When looking at a landscape of practice from above, the CoP became one of the many social learning spaces of a landscape. A social learning space is any configuration of individuals who engage in a learning partnership in relation to a certain domain. The movement of zooming out takes a landscape perspective, which affords an understanding of the learning potential present when the different boundaries of the landscape are brought into contact with each other. These boundary encounters, by bringing fresh perspectives, provide opportunities to answer the critique that CoPs can lead to the reproduction of existing practices rather than creating new knowledge (Cushion, 2008). The other movement, zooming in, focused on what makes a social learning space valuable to the individual who is navigating across the landscape. For instance, in this new development of the theory, Wenger-Trayner and WengerTrayner (2015) recognized the importance of the role of the systems convener. A systems convener is the person charged with developing learning capabilities within the landscape of practice, harnessing synergies among, and nurturing, social learning spaces. The theorists developed the original version of the value creation framework (VCF; Wenger, Trayner, \& De Laat, 2011) as a tool to promote and assess value in social learning spaces. 
Researchers in parasport coach development have repeatedly found that formal learning opportunities for parasport coaching are rare and, for the most part, much too generalized to provide practical information for coaches (e.g., Cregan, Bloom, \& Reid, 2007; McMaster, Culver, \& Werthner, 2012). Moreover, learning through interactions with others is a popular avenue for parasport coach learning (Duarte \& Culver, 2014; Taylor, Werthner, \& Culver, 2015). A social learning approach, mostly proposing the use of CoPs, has proven to be of value for coach development outside of parasport (Culver \& Trudel, 2006; Garner \& Hill, 2017). Other coach education researchers have proposed that a systems perspective is required when designing programs for coaches (Culver, Werthner, \& Trudel, 2019); therefore, a landscape approach to social learning in parasport coaching is warranted. Duarte, Culver, and Paquette (2020b) used such a perspective to map the landscape of practice of wheelchair curling (WC) coaches to better understand current gaps, learning structures, and important actors who might serve as mentors. As for leadership in social learning spaces, such as CoPs, researchers in coach development have pointed out the fragility of the CoPs in the absence of ongoing leadership, with the collaboration among coach participants endangered after the departure of the leaders who initiated and facilitated the meetings (Culver et al., 2009; Culver \& Trudel, 2006). Duarte, Culver, and Paquette (2020a) examined leadership in a social learning space for parasport coaches, describing the crucial contribution of the systems convener as a leader in leveraging strategic and enabling learning values in the framing of the social learning space. Relating to the VCF, the coach development literature to date (Bertram et al., 2016, 2017; Vinson et al., 2019) has been limited to using the original version of the VCF (Wenger et al., 2011); therefore, an in-depth examination of the application of the most recent VCF is justified.

In its most recent and expanded version, the VCF includes four pairs of learning value cycles, which address a range of dimensions (see Table 1; Wenger-Trayner \& Wenger-Trayner, 2020). A social learning space involves the participants in a learning partnership. For the first pair of value cycles, immediate and potential, value can be examined as the experience of partnership (immediate) and its output (potential; WengerTrayner \& Wenger-Trayner, 2020). These values can be positive, negative, or neutral. For example, stories shared with a social learning space can provide positive potential value if they help participants avoid "reinventing the wheel," but negative potential value might result if the application does not transfer to the participants' context. This sort of examination of the value created at different value cycles affords a much more in-depth understanding of learning in social learning spaces.
The current paper expands on the existent literature in three ways. The first is in line with the ongoing evolution of social learning theory and the VCF; whereas previous papers in sport have focused on five value cycles (i.e., immediate, potential, applied, realized, and transformative), this paper explores three pairs of value cycles: (a) immediate and potential, (b) applied and realized, and (c) orienting and transformative (Wenger-Trayner \& Wenger-Trayner, 2020). Given the purpose of this paper to report on the outcomes of a social learning intervention, ${ }^{1}$ the fourth pair of value cycles (i.e., strategic and enabling), which is important for framing social learning interventions, is reported on elsewhere (see Duarte et al, 2020a). Second, the paper shows in a concrete way how coaches from different contexts can benefit from a social learning space. Third, it explores how the value creation dimensions might represent learning value that goes beyond behavior change. A pivotal contribution of the $\mathrm{VCF}$ is that it highlights changes in more nuanced manners, such as changes in a learner's attitude and knowledge, even if the learners have not yet changed practice. This idea aligns well with other important learning theories. For example, Jarvis (2009) defined learning as cognitive, emotional, and practical changes in a person.

The purpose of this paper is to report the value created throughout a social learning space intervention with Canadian WC coaches. Specifically, we sought to answer the following question: What dimensions of learning values were created for those who participated in the intervention? This paper is the third part of a larger project that aimed to increase the learning capability of the Canadian WC landscape, reporting the outcomes of the intervention. The data used for this third paper are the same as those for the second paper because both of these papers relate to the social learning space intervention.

\section{Methodology}

This research is situated within the participatory paradigm and makes use of collaborative inquiry (Bray, Lee, Smith, \& Yorks, 2000; Heron, 1996). In collaborative inquiry, reality is participative and is cocreated by the mind and the surrounding environment through cycles of reflection and action that shape the experiences of all the actors within the project (Heron, 1996). In other words, the authors and participants coconstruct knowledge every time they engage with each other; therefore, every data generation opportunity is also believed to have a potential impact on the participants' learning (Bray et al., 2000). In this sense, every interaction between the participants made up the intervention. Thus, this social learning intervention comprised online camps, interviews, discussions, and so on, with no one activity taking priority over another.

\section{Table 1 Learning Value Cycles With Descriptors and Dimensions}

\begin{tabular}{lll}
\hline Value cycle & Descriptor & Examples of dimensions \\
\hline Immediate & Your experience of the social learning space & Sense of inclusion; exciting company \\
Potential & What you get out of the experience & Resources; social capital \\
Applied & What you do with the potential value & Being more assertive; reuse \\
Realized & The result of that application & Personal, collective, and organizational levels \\
Orienting & Interactions with the broader landscape & Participants' contexts; inherited boundaries \\
Transformative & Broader or deeper effects & New identities; redefinition of success \\
Strategic & Conversations with stakeholders & Strategic contexts; intentionalities \\
Enabling & What makes this all possible & Robust back channel; transparency \\
\hline
\end{tabular}

${ }^{\text {a }}$ This pair of values is addressed in Duarte et al. (2020a). Other examples of the value created are presented in the "Findings and Discussion" section. 


\section{Methods}

\section{Participants}

The social learning space intervention involved a peer learning group (PLG) composed of 25 participants. The participants included 16 WC coaches, six Curling Canada technical leaders, and three researchers. The WC coaches were recruited through purposeful and snowball sampling strategies (Sparkes \& Smith, 2013). The group of coaches accounted for a majority of the population of active WC coaches in Canada. This group included seven females and nine males $(R=50-70 ; M=59.5$ years $)$ from seven Canadian provinces and 14 cities. The years of coaching experience varied greatly across the able-bodied curling $(R=1-25$; $M=19.5$ years $)$ and WC ( $R=1-12 ; M=6.5$ years $)$ contexts. More details of their collective experiences are provided in the findings presented below. Three of the Curling Canada technical leaders included the High-Performance Director, the Head Coach, and the Team Manager $(R=35-65 ; M=52.5$ years $)$ who had worked with the WC national team program (NTP) for more than a decade. Two of the technical leaders were sport sciences providers. Another technical leader was involved with coach development. The Curling Canada technical leaders interacted with the PLG to provide guidance and support for the coaches' learning endeavors. Further information on this group is presented in the last vignette. Finally, the three researchers (R1, R2, and R3) comprised the last group of participants. All of the researchers have experience with coach development and disability sports ( $R=5-10$ years; $M=8.3$ years). $\mathrm{R} 1$ acted as the systems convener (see Duarte et al, 2020a for more information about the role of the systems convener). R2 was the academic supervisor of R1. At the time of the study, R3 acted as the liaison between the other researchers and Curling Canada because of his official involvement as a technical leader, who was responsible for coordinating all of the sport science providers, research and innovation programs, and mental performance services for the Curling Canada national teams (able-bodied and WC).

\section{Ethics}

The University of Ottawa's research ethics board granted ethical approval, and all participants signed an informed consent form. All Curling Canada technical leaders but one authorized the use of their names. Because of this, except for the one participant, we chose to disclose only their specific roles. For the one participant, we referred only very broadly to their role. Due to a potential power issue between the coaches and the Curling Canada technical leader/ members, several initiatives were taken. For instance, R1 was the only person to have access to the raw data of the individual interviews. Moreover, during the first online camps, which resembled webinars, whenever a participant coach had a question, the questions were sent to R1, who posed the questions to facilitators. After a few online camps, the participant coaches perceived the risks as nonexistent and decided to renegotiate confidentiality and anonymity (Williamson \& Prosser, 2002) to address the facilitators directly.

\section{Making Meaning and Constructing Knowledge}

In collaborative inquiry, which is a form of participatory action research, data generation and analysis are inseparable due to the intricate nature of meaning making (Bray et al., 2000). Typically, participants in this type of inquiry will discuss a certain issue and reflect on it collectively, arriving at a potential action that can be tested in practice. Subsequently, the inquiry will debrief that application, reflecting further how it might advance knowledge. Given the cyclical nature of collaborative inquiry, the framing (planning and shaping of the learning agenda) and assessment (evaluation of learning value) overlapped as the cycles of reflection, individual and collective, helped shape the subsequent activities during a 13-month time frame. The following sections outline the nature of this collaborative inquiry intervention: how the data were generated and how knowledge construction occurred, including the details about the presentation of the findings as composite vignettes, and considerations regarding trustworthiness.

Data generation. In line with the collaborative inquiry approach, data were generated through the PLG learning activities as well as a multitude of other techniques including interviews, focus groups, observations, and online posts. It is important to understand that all methods of data generation were treated as equally important for meaning making.

Learning activities. The learning activities described here, online group meetings and online camps, provided the context for much of the learning value created (see "Findings and Discussion" section). Four online group meetings were facilitated by R1 and lasted approximately $90 \mathrm{~min}$ each. These online group meetings brought coaches together within a collaborative space for knowledge creation (e.g., by the coaches raising their concerns and, in some cases, critiques of the WC community). The meetings were driven by the coaches' learning needs and served to shape the more formally structured online camps (i.e., webinars; see Duarte et al., 2020a). Eight online camps were held, also lasting approximately $90 \mathrm{~min}$. Four of these camps involved a speaker invited by the group to address a specific topic, and the other four were led by PLG coaches. Online tools. The intervention used four online tools (see details in Duarte et al., 2020a): GoToMeeting (Pro 25), Basecamp, Survey Monkey, and Doodle. The selection of these tools was based on two criteria: user friendliness and cost. GoToMeeting was the only tool with a paid subscription, and it was provided by Curling Canada. GoToMeeting served to host the online group meetings, online camps, and interviews due to its capacity to support audio from up to 25 attendants and live video for up to seven attendants at a time. It was also used to record both the audio (all users) and presenter screen during the meetings and interviews. Basecamp is a project management tool used by the PLG participant coaches to stay abreast of the learning activities (e.g., forums, group calendar) and as a resource database (e.g., videos of online camps, presentations). Survey Monkey is a survey tool that was used after the online camps for feedback on the camps and to stimulate reflection on the application of the content presented. Finally, Doodle is a short survey tool that was used to facilitate scheduling.

Other data generation techniques. Aligned with collaborative inquiry (Bray et al., 2000), our experience trail included a multitude of data generation techniques: in-depth interviews, focus groups, observations (e.g., field notes and reflections), and analysis of the online entries on a shared website. First, in-depth semistructured interviews occurred with the coaches at three different moments of the inquiry: at the beginning $(N=15, R=24-119 \mathrm{~min})$, midpoint $(N=10, R=15-57 \mathrm{~min})$, and end of the intervention $(N=13, R=$ 24-54 $\mathrm{min})$. While the number of coach participants fluctuated and actually increased over the 13-month intervention, not all of the coaches were available for three interviews. Seven coaches participated in all three interviews, and eight participated in two 
interviews. These in-depth interviews utilized semistructured guides and were conducted in person or online. The different interview guides were created using the VCF (Wenger et al., 2011). The first interview included questions to understand the coaches' pathways (e.g., Tell me a little bit about your curling experience); the second interview explored the coaches' experiences within the intervention (e.g., user friendliness, barriers to participation); and the final interview assessed the value created throughout the intervention (e.g., How did you benefit from this experience?). Second, two focus groups were held and utilized similar interview guides based on the VCF. The first focus group (60 min) occurred during the second National Championship R1 attended and explored the perspectives of seven coaches concerning the intervention. The second focus group (66 min) included the perspectives of three Curling Canada technical leaders (NTP coaches) and was conducted online. Third, observations took place at the three different competitions R1 attended. Despite the handwritten field notes taken during the 14 days of competitions, the experience of being a participant observer immersed in the WC culture afforded R1, through the constant interactions and informal conversations, a deep understanding of the sport's context. Fourth, the analysis included a total of 1,001 online entries of the coaches and Curling Canada technical leaders, such as posts, comments, and answers to prompts across four different online tools.

Constructing knowledge. All three researchers work in the area of coach development and come to this from a constructivist lens. Braun, Clarke, and Weate's (2016) thematic analysis coupled with an interpretative analysis (Bray et al., 2000) was used to make sense of the 615 single-spaced pages of data. Braun et al.'s (2016) thematic analysis phases include (a) familiarizing, (b) general initial codes, (c) searching for themes, (d) reviewing themes, (e) defining and naming themes, and (f) producing the report. The updated VCF (Wenger-Trayner, Wenger-Trayner, Cameron, Eryigit-Madzwamuse, \& Hart, 2017) provided the theoretical scaffold that allowed the researchers to frame and analyze the intervention using a deductive approach. Thus, the learning values were themes, and as the process evolved, we made use of the coaches' location within the WC landscape metaphor to explain how value was created by and for the coaches (see Figure 1). In this way, the two types of analysis, deductive thematic and interpretative, were integrated. NVivo 12 (QSR International, Melbourne, Australia, 2018) was the qualitative data analysis software used to organize the many different pieces of data. The observations (e.g., field notes and reflections) were scanned and uploaded as PDF files. The interviews, focus groups, and online group meetings were audiotaped and transcribed. Further details on how the intervention was framed can be found elsewhere (Duarte et al., 2020a).

Composite vignettes. In sport, one of the first examples of vignettes was Denison's portrayal of retirement from high performance (HP) sport (Denison, 1996). Denison provided few details about how he composed the three narratives that were based on indepth interviews with 12 retired athletes. Since then, various researchers have used the technique (e.g., Deal \& Camiré, 2016; Winchester, Culver, \& Camiré, 2011). For example, based on 31 interviews, Winchester et al. (2011) portrayed how teacher-coaches learn to coach by creating three different profiles typical of their participants. A similar approach was taken in this study, in

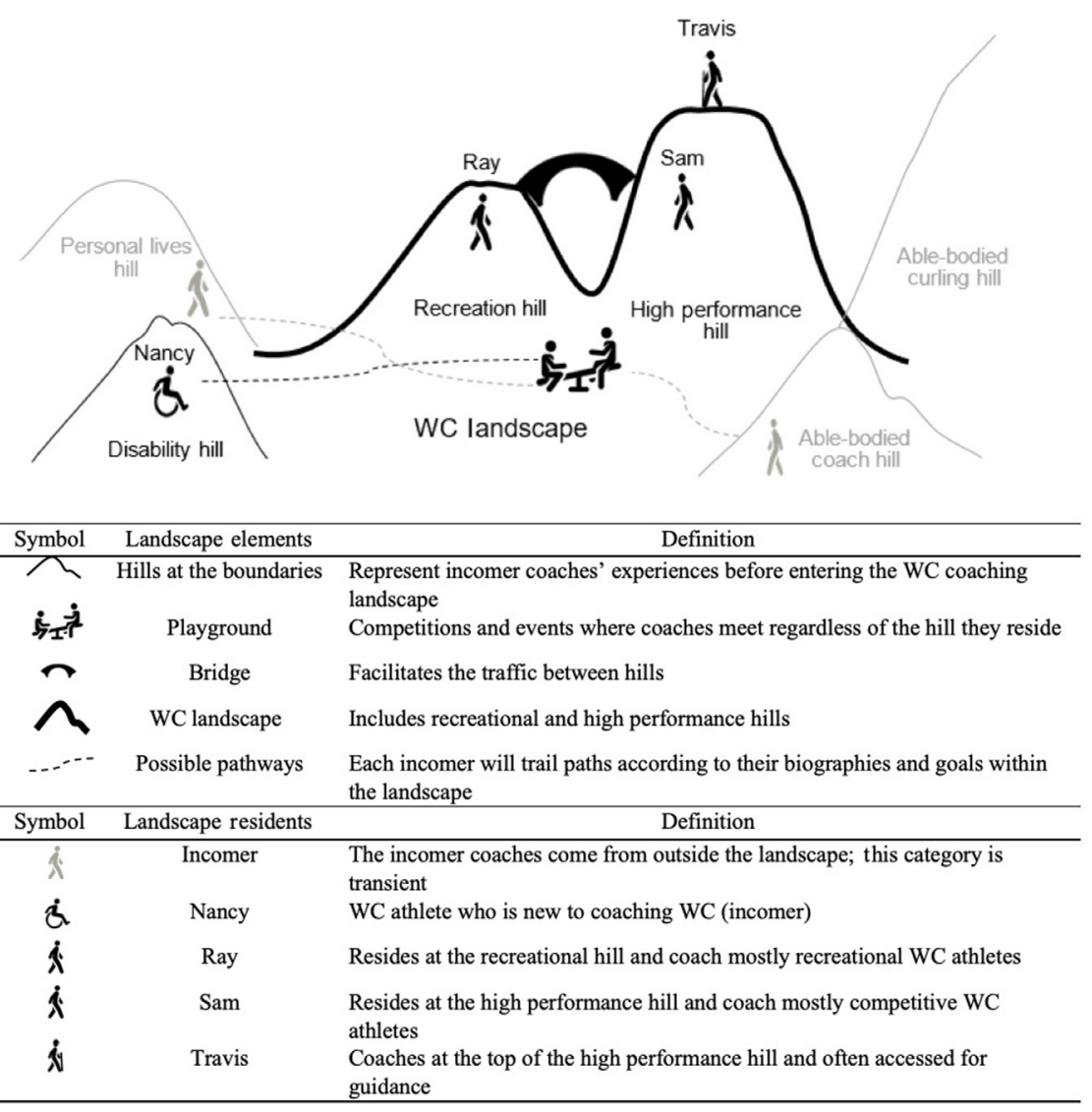

Figure 1 - Landscape elements and residents. Adapted from Duarte, Culver, \& Paquette (2020b). WC= wheelchair curling. 
which the findings are presented as four composite vignettes. Among the different vignette formats (i.e., snapshot, portrait, and composite vignettes), we chose the composite vignette as it unifies multiple experiences into a single experience (Ely, Vinz, Downing, \& Anzul, 1997).

The construction of the vignettes occurred toward the later phases of the thematic analysis (Braun et al., 2016), and it was a collaborative effort between the researchers, especially R1 and R2, both of whom were part of the PLG and had had extensive involvement within the WC context. The process of writing the composite vignettes involved the act of highlighting the major themes identified during the thematic analysis. An example of how the vignettes were crafted and the use of the many data generation techniques is presented in the Appendix. For instance, Nancy's vignette was crafted by 23 codes from different data generation techniques including observations at competitions, interviews, and focus groups, and the questions utilized to gather data. The profiles of the coaches below comprise shared characteristics and life stories related to their WC coaching context (i.e., their location within the landscape). Adding to this, Figure 1 expands the landscape metaphor as it presents the coaches' residencies and possible pathways, represented by the dotted lines of incomer coaches to the WC landscape. Given the varied biographies of the incomer coaches and their different entry points into the WC landscape, the composition of an incomer vignette posed the greatest challenge. As it happened, Nancy's story represents all of the recreational coaches in the group as well as all those living with a disability. Quotations from the various data sources were used to contextualize the experiences portrayed in the vignettes (Ely et al., 1997). Finally, at least three coaches inspired the writing process of each vignette.

\section{Validity}

For thousands of years, storytelling and narratives have been used effectively to communicate knowledge. However, only in the last few decades has the credibility of vignettes emerged and been supported as a legitimate way to report qualitative data (Ely et al., 1997). Vignettes are popular due to their capacity to capture the reader and effectively transmit participants' attitudes, beliefs, and perceptions (Ely et al., 1997). With a relativist approach framing our efforts toward quality standards for qualitative research (Burke, 2016), the ability of composite vignettes to improve the accessibility of the research findings was justified. Furthermore, the possibility for coach developers to make naturalistic generalizations (Sparkes \& Smith, 2013) through reading the vignettes was a plausible aim given previous research (e.g., Deal \& Camiré, 2016; Paquette, Trudel, Duarte, \& Cundari, 2019).

\section{Findings and Discussion}

The vignettes are presented in the form of a dialog between a fictional coach and R1. The major themes found throughout the meaning making and knowledge construction guided the creation of Figure 1 and these vignettes. As noted above, the analysis was conducted according to the coaches' residency in the landscapethat is, their coaching context (see Figure 1); therefore, each vignette is immediately followed by a discussion of how the PLG created value for the coaches in the specific context. It is important to recognize that although our vignettes represent coaches as newcomers, recreational, and HP, this does not signify that coaches move in a linear fashion in their development. Trudel and
Gilbert (2013) explain that a coach can move from HP in one coaching context to newcomer in another context, as would be the case for a National team coach of able-bodied curling who moves into the WC context. Interwoven within each vignette are some additional findings about the major contextual factors of the WC landscape (see also Duarte et al., 2020b). Each of the vignettes discussed separately answers the research question: What dimensions of learning values were created for those who participated in the intervention? The learning values discussed following each vignette are the ones that were most significant for the coaches in the respective context; however, some of these values were also experienced by the coaches in the other contexts. To facilitate the visualization of the value cycles discussed in the vignettes, Table 2 defines the dimensions for each context.

\section{Nancy, the Incomer: “I Don't Know What I Don't Know!"}

R1: Tell me a little bit about your curling experience.

Nancy: I got involved with WC due to my own impairment. I tried many different sports like wheelchair basketball, but at my age (50s), the stamina isn't there anymore. A "wheelie" friend of mine kept bugging me to join the team because it is always a struggle to find wheelchair users who want to stay seated inside the freezer [laughs], I mean on the ice sheet. So, I showed up and had so much fun! I was hooked by the sense of community! Locally, we always played against able-bodied teams because there aren't any other local wheelchair teams; well, not even adapted clubs. I travelled to a few tournaments within five hours from home. How bizarre that one week we played against able-bodied teams in our recreational league at the club, and the next we competed against teams that we had seen on TV at the Paralympic Games! And sometimes, we even beat them!

\section{R1: Yes, that is bizarre! What else about competitions was remarkable?}

Nancy: At the nationals, Curling Canada requires that every team brings a coach. Actually, the difficulty of finding a coach to work with us is what motivated me to become a coach.

\section{R1: What were your initial thoughts and goals for participat- ing in the intervention?}

Nancy: At first, I thought it would be an opportunity to meet other coaches and if there was an open coaching spot on Team Canada, why not? I thought being a wheelchair user, I could be the voice of people with disabilities within the NTP. Of course, that thought did not last. Reading all the topics on Basecamp and online camps was quite overwhelming at times. The amount of information helped me realize that I don't know what I don't know. [laughs] I was in way over my head. The amount of knowledge the NTP coaches have is really impressive and it did bring much more appreciation for what they are doing with the national team.

\section{R1: On that topic, can you describe your participation in these different learning activities?}

Nancy: I participated in every activity I could. It felt so great to be part of the community; I wanted to experience it fully. I was 
Table 2 Dimensions of Value Created for Participants

\begin{tabular}{|c|c|c|c|}
\hline Value cycle & $\begin{array}{l}\text { Dimensions of } \\
\text { value created }\end{array}$ & $\begin{array}{l}\text { Elements of } \\
\text { learning }\end{array}$ & Definition of each dimension \\
\hline \multirow[t]{4}{*}{ Immediate } & Sense of inclusion & Emotive & Feeling of companionship with people who value your participation \\
\hline & Exciting company & Emotive & $\begin{array}{l}\text { Delight people feel when involved with those holding state of the art knowledge in an } \\
\text { area important to them }\end{array}$ \\
\hline & $\begin{array}{l}\text { Engagement with } \\
\text { other perspectives }\end{array}$ & Cognitive & Exposure to other contexts and points of view within the landscape \\
\hline & $\begin{array}{l}\text { Generational } \\
\text { encounters }\end{array}$ & Cognitive & Newcomers with fresh perspectives and old-timers with rich experiences \\
\hline \multirow[t]{4}{*}{ Potential } & Resources & Cognitive & $\begin{array}{l}\text { Access to artifacts produced or shared by the community, such as documents and } \\
\text { tools, tailored to WC }\end{array}$ \\
\hline & Social capital & Cognitive & $\begin{array}{l}\text { One's capability to increase their personal connections or reputation, as well as } \\
\text { understanding the roles people play within a landscape }\end{array}$ \\
\hline & Insights & $\begin{array}{l}\text { Cognitive and } \\
\text { emotive }\end{array}$ & Nuanced insights from the group \\
\hline & Potential collaborators & $\begin{array}{l}\text { Cognitive and } \\
\text { emotive }\end{array}$ & $\begin{array}{l}\text { Opportunity to establish common ground and leverage synergies, leading to potential } \\
\text { opportunities for collaboration }\end{array}$ \\
\hline \multirow[t]{4}{*}{ Applied } & Being more assertive & $\begin{array}{l}\text { Practical and } \\
\text { emotive }\end{array}$ & Speaking more confidently with stakeholders \\
\hline & Reuse & Practical & Templates, procedures, and documents repurposed to match another's practice \\
\hline & $\begin{array}{l}\text { Harnessing of } \\
\text { synergies }\end{array}$ & $\begin{array}{l}\text { Practical and } \\
\text { cognitive }\end{array}$ & Alignment of resources to achieve common interests \\
\hline & $\begin{array}{l}\text { Leveraged } \\
\text { connections }\end{array}$ & $\begin{array}{l}\text { Practical and } \\
\text { emotive }\end{array}$ & Collaborating with participants in a joint project \\
\hline \multirow[t]{4}{*}{ Realized } & Personal level & Emotive & Personal satisfaction of being part of the community \\
\hline & Stakeholders & Practical & $\begin{array}{l}\text { People outside of the social learning space who benefit from the value created by a } \\
\text { participant }\end{array}$ \\
\hline & Collective level & $\begin{array}{l}\text { Emotive, cognitive, } \\
\text { and practical }\end{array}$ & Influence on other group members \\
\hline & Organizational level & Practical & Contributing to an organization's mission \\
\hline \multirow[t]{4}{*}{ Orienting } & $\begin{array}{l}\text { Biographies and } \\
\text { identities }\end{array}$ & $\begin{array}{l}\text { Cognitive and } \\
\text { emotive }\end{array}$ & $\begin{array}{l}\text { Leveraging the broader identities and histories that people bring to see things in new } \\
\text { ways }\end{array}$ \\
\hline & Participants & Cognitive & Exploring the various contexts and implications for learning together \\
\hline & Personal networks & $\begin{array}{l}\text { Cognitive and } \\
\text { emotive }\end{array}$ & $\begin{array}{l}\text { Exploring and leveraging connections that people have across the landscape to enrich } \\
\text { the space }\end{array}$ \\
\hline & Inherited boundaries & $\begin{array}{l}\text { Cognitive and } \\
\text { practical }\end{array}$ & Recognizing and addressing boundaries that manifest within the social learning space \\
\hline \multirow[t]{4}{*}{ Transformative } & New identities & Emotive & Transforms how individuals experience the world \\
\hline & History and culture & Emotive & The effects learning has on mindsets and historical narratives \\
\hline & $\begin{array}{l}\text { Redefinition of } \\
\text { success }\end{array}$ & $\begin{array}{l}\text { Emotive and } \\
\text { cognitive }\end{array}$ & Mindset changes that lead participants to rethink their participation in the landscape \\
\hline & Institutional change & Practical & Changes to the organizational structures and procedures \\
\hline
\end{tabular}

Note. For all but orienting value, the dimensions listed follow the order of the four vignettes (e.g., immediate: sense of inclusion is for Nancy; exciting company is for Ray, etc.). For orienting value, the dimensions presented are for all the PLG participants. PLG= peer learning group; WC = wheelchair curling.

so impressed with everything I heard and read that at first, I thought twice before commenting or asking. Actually, it was good that during online camps I could send my questions in without asking directly. I didn't want to be viewed as a newbie. In the last few months, I'm way more confident.

R1: How so? Can you expand on what ways you have benefited from the PLG?

Nancy: Oh, boy, I benefitted in so many ways. Actually, I have a great story that happened during a major competition. At our competitions, opposing coaches are side-by-side watching the game. So, as an athlete, when I started coaching, I would never sit close to the coaches like a "spy." But after a few PLG meetings, I felt confident to ask if I could sit behind them. The coaches were very welcoming and invited me to sit not behind, but beside them. As the game went on, they shared among themselves some tips on how the teams should be playing, and even, to my surprise, asked my opinion a few times. Being part of the group made me more confident to join in conversations and to feel that I belong.

Value created for incomer coaches. The incomers were the most diverse group among the participant groups in terms of their 
origin, with one participant coming from each of the different boundary hills (i.e., disability hill, personal lives hill, able-bodied hill). The incomers' learning values were organized in five dimensions: (a) sense of inclusion (immediate), (b) resources (potential), (c) being more assertive (applied), (d) personal (realized), and (e) new identities (transformative). First, the WC community is small and spread across Canada; thus, Nancy's participation in activities related to WC resulted in the dimension sense of inclusion. The importance of inclusion is heightened in parasport by the lack of athletes and teams, and by the geographical challenges to competing (e.g., Kohe \& Peters, 2017). Lave and Wenger (1991) mentioned how apprentices felt at ease asking questions to more advanced peers instead of to masters. That sense of inclusion, which is an indication of the emotional element of learning for Nancy (Jarvis, 2009), is a precursor to her being able to ask questions, without which she could not have the possibility of changing her behavior. Second, the resources dimension is evident in the documents and tools tailored to WC. The PLG posted 1,001 entries on Basecamp, 12 recorded hours of the online camps, and 46 documents produced and shared, which was of particular benefit to the incomers. Third, as Nancy's confidence increased, she became more assertive, especially vocally, and engaged in both online and in-person situations. The assertiveness described in the vignette was observed in other studies in which CoPs expedited the familiarity of newcomers with the community (Bertram et al., 2017). Fourth, Nancy experienced realized value at the personal level as she felt the personal satisfaction of being part of the community. Fifth, Nancy's new identity as a WC coach shaped the way she engaged with other coaches and allowed her to join conversations that she would not have joined as a WC athlete.

\section{Ray, the Recreational Coach: "Coaching Wheelchair Curling Is so Complex!"}

\section{R1: How did you start coaching?}

Ray: I started coaching because of my two sons; from little rocks until they went to the university. Coaching my kids had a big influence as I was able to see their development from recreational participants to competitive athletes, and now as lifelong participants. I made many lifelong friends and decided to continue coaching. I took the National Coaching Certification Program Level Two certification and the courses for Level Three. Maybe one day I will continue to L3 certification. Now that I am retired, I am at the curling club many nights per week, volunteering in other areas as well. A few years ago, a wheelchair athlete asked me if I would coach his team. I was a bit intimidated at first but decided to give it a try. Our team does not meet very often as two of the athletes live two hours from our club. Team practices are once or twice a month and I am on ice once a week with two of the athletes. So, it took me a while to figure out how to coach them properly. Some of my athletes are working toward the Paralympics and others are playing for fun, requiring adjustments to the teams' goals.

\section{R1: Really? With such limited time and broad team goals, how did you learn about coaching?}

Ray: Coaching WC is so complex. Every athlete is different, the rules are different, many different (dis)abilities. So, I learn from the athletes, talk to other coaches at my club, and at competitions. The athletes are the experts on their disabilities; so, I listen a lot! My club has former able-bodied national champions who are very eager to help. But the fact that WC doesn't have sweeping makes the game very different. The competitions are a great source of learning. On one hand, you have very organized teams with assistant coaches taking care of their homemade lunches and some have Paralympic gold medalists retired from other sports. On the other hand, other teams have athletes eating fries and engaging in behaviours that are not at all linked to high-performance. So, at competitions you can learn by observing everything within and between these two streams.

\section{R1: What were your goals for participating in the intervention?}

Ray: I believe there are many gaps between what we know and what is happening at the high performance (HP) level. One of the major reasons to participate was to be able to see what other people were doing. Of course, it is nice to see what is happening with Team Canada, but my team is at the level that we need to work on the big pieces versus the small details. We still have to adjust some major gaps like upping the amount of practices, especially for injury prevention. It's hard to prepare athletes to play two games per day for five days in a row when they are only practicing twice a week.

\section{R1: How do you evaluate your participation in the PLG?}

Ray: I attended many of the learning activities and enjoyed reading other coaches' experiences on Basecamp. For some time, I thought the NTP was a closed club that would not share info with people who are outside the group. So, I was very curious, and I am very pleased with how that sharing part happened. An example of something that I changed was the use of drills from Team Canada. After the online camp with the NTP coaches, we started to be more deliberate in our practices. Instead of having scrimmages or games with able-bodied teams, I would set-up some drills for players to execute.

\section{R1: How did you benefit from this experience?}

Ray: I believe that what has changed the most is how easily I have my questions answered. Before, I felt like I was back in the day when, if I had a question, I would send a message in one of those cylindrical pneumatic tubes and it would get lost somewhere; like the provincial organization took a month to reply and say that Curling Canada should be answering or something like that. With the PLG, I had access to many coaches, and sometimes after a few hours I get an in-depth answer that I can apply right away. It's the end of the lost message and the middle-man. Also, it was very good to have access to the professional development credits from my home. Continued education costs a lot of money since it means travelling and other logistical expenses which add up pretty quickly, especially when you're a retired, volunteer coach.

Value created for recreational hill coaches. The coaches on the recreational hill did have many experiences within the WC landscape that allowed them to have greater access to the WC community than the incomers, but they were less engaged than the coaches on the HP hill. The five dimensions of learning values prevalent for these coaches were (a) exciting company (immediate), (b) social capital (potential), (c) reuse (applied), (d) stakeholders (realized), 
and (e) history and culture (transformative). First, since Ray did not attend many competitions, being involved with a group of coaches who are passionate about WC was highly satisfying, and it also provided him with access to individuals from the NTP. Immediate value is an excellent indicator of how emotional changes are important aspects of learning. Moon (2001) theorizes that learners who are excited by a learning opportunity show a motivated orientation toward learning. Second, Ray experienced social capital through the PLG providing him with online access to many coaches from across the country with expertise in physiotherapy, nursing, sport doping, statistics, and so on. This increased access facilitated an understanding of who to contact in case of a coaching issue (Occhino, Mallett, \& Rynne, 2013; Gilbert \& Trudel, 2001). Third, for the reuse dimension Ray adopted the drills presented and shared by the NTP during online camps. While the application of a given artifact into a person's context is never straightforward, and adapting it requires reflection (Moon, 2001; Schön, 1983), the online interactions supported Ray in his application. Fourth, continuing with the drills example, the stakeholders' dimension was illustrated by Ray's application of the NTP drills which provided their athletes (stakeholders) with more deliberate practices based on the drills. Fifth, in relation to the history and culture dimension, Ray initially perceived the NTP as a closed and secretive group (Duarte et al., 2020b). Ray's participation in the learning activities led by the NTP changed Ray's perspective of the NTP from secrecy to transparency.

\section{Sam, the Coach in the Middle of the HP Hill: "At My Stage, I Need to be Looking for Nuances in How to Coach"}

\section{R1: Tell me how you got involved with curling.}

Sam: I have curled from a young age and started coaching able-bodied curling since, oh wow, I am getting old [laughs], since the 80s; coaching ladies' teams, men's teams, and junior teams. Some of the teams I work with did well at the provincial level. I really enjoy learning, so I took my coaching certification level three and what they now call the Advanced Coaching Diploma. With the friendships I established, I got invited to become a learning facilitator for the National Coaching Certification Program. Also, I went a couple times to the Scotties; the highest women's competition in Canada. Funnily enough, last year, the current Olympic gold medallists did not come to the event because they lost the qualifying match at their provincial championships. That shows you how competitive curling is in Canada.

R1: Wow, only in Canada, Eh? I was going to ask you how you learned to coach curling. It seems that you're very competent at what you do.

Sam: Let's say, I'm fortunate enough to be surrounded by great people who are great mentors and whom I can call friends. I have been around the NTP coaches for many years. This has provided me with a sound network of sport science providers who I can call upon and use as a sounding board. Outside curling, I have a friend who teaches adaptive physical education at the university, so we get together once in a while to chat. Of course, when you coach NTP athletes you have easier access to the latest intel because they bring a lot of insider knowledge from the competitions they attend. I also got invited to NTP training camps which are the best place to learn the cutting edge in terms of sport sciences!

R1: Based on your previous comments, many of the learning opportunities provided by the PLG were already available to you. What kinds of new benefits have you experienced if any through the PLG?

Sam: I've been teaching coach education modules for many years which has allowed me ongoing opportunities to reflect on my role as coach and on the advancements of the sport. The "aha" moments that some of the less experienced coaches had during the online camps, I had already experienced them at different camps or competitions. While much of the information provided was not new, at my stage, I need to be looking for nuances in how to coach. So, to be specific, during an online camp the NTP coach mentioned a change in how they score shots. That led me to connect with them later and discuss the change. The NTP coach told me it was because of the analytics from the international competitions they attended that year. If I had not been at the online camp, I would have lost the opportunity to reflect on these changes. So, I would say the biggest benefit was to engage monthly with all of these great people. Can I say that I have changed the way I coach? I don't think so. Have I changed the way I engage with the other coaches? For sure, and that's the biggest benefit.

R1: Does that have any relation to what we talked about during the mapping interviews regarding coaches keeping secrets close to their hearts?

Sam: Absolutely! At first, I was skeptical and not very convinced I would share what I have, but I was also very curious to see how some of the other coaches would behave. If they would be willing to let some information out. They surely did. It was quite impressive to see all of the conversations on Basecamp and people sharing their drills, tools, Curling Canada sharing coaching manuals, and the NTP coaches coming and speaking openly about their struggles and how to surmount them. I mean, don't get me wrong, people were not sharing how they would play during a given game or what their teams' strengths and weaknesses are, but other than that they were sharing the whole thing. In fact, at the statistics online camp, the presenter shared the team's real performance data. All the synergies being created inspired me to share as well, and that's when I offered to lead that online camp. I felt good sharing my expertize and alleviating the pressures some recreational coaches face at their clubs. Actually, yesterday I got an email from a coach asking to help him out related to the online camp content. So, in that perspective, what I have changed is my view of how competitive coaches, like myself, can collaborate for the good of the sport. Beyond that, there is always that fear that you do not want to miss out: i.e., you don't know what you don't know! Curling is a sport that is in constant evolution, and even more so in wheelchair; I wanted to be in tune with the latest information from the NTP.

Value created for the coaches around the middle of the HP hill. The coaches around the middle of the HP hill are lifelong learners who have been coaching in both the curling and WC landscapes in different contexts for decades. The five dimensions of learning values for coaches around the middle of the HP hill were (a) engagement with other perspectives (immediate), (b) insights 
(potential), (c) the harnessing of synergies (applied), (d) collective (realized), and (e) the redefinition of success (transformative). First, for Sam, who coached mainly HP athletes, the engagement with other perspectives dimension refers to the engagement in the PLG increasing Sam's knowledgeability of the recreational context. Second, Sam looked for nuanced insights from the group. More specifically, Sam was attentive to the comments from the NTP experiences at the World Championships and the Paralympic Games, as well as the challenges faced by coaches on the recreational hill. Third, the cocreation of knowledge through leading an online camp is how Sam harnessed synergies and aided in the alignment of resources to achieve common interests. Fourth, Sam created value for the collective by sharing various resources on Basecamp. This increased the knowledgeability of the other coaches in the PLG. While other studies have referred to realized value associated with athlete outcomes (Bertram et al., 2016; Vinson et al., 2019), it is important to understand that realized value can be a small step on the way to making a difference (Wenger-Trayner \& Wenger-Trayner, 2020). In this case the other coaches were, subsequent to Sam's sharing, better informed about where in the landscape to go for help. Finally, Sam experienced the redefinition of success dimension. Initially, Sam was skeptical about collaboration among opponents at the competitive level. This type of shift from a focus on improving one's team to supporting the growth of the sport through collaboration is aligned with the findings of other coaches' CoP studies (Callary, 2013; Culver et al., 2009).

\section{Travis, the Coach at the Top of the HP Hill: "Coaching Is Coaching! You'll Coach Each Individual's Abilities"}

\section{R1: Tell me how you got involved with curling.}

Travis: I started throwing rocks a long time ago and the passion for the game led me to experience competitions at different levels. I consider myself a keen student of the sport and performance; every time I saw a book, I had to buy it, every conference and coaching course I had to attend. I guess my passion for learning the game is what led me to coaching. For me it is pretty obvious that coaching is teaching, with the benefit that the best way to learn is to teach. One thing led to another and once you start connecting with other sport lovers, doors open.

\section{R1: How so?}

Travis: Well, there are so many stories. I have been involved with Team Canada since the first Paralympics. So, when the World Curling Federation announced the creation of WC, we needed to develop the sport in Canada. Curling Canada leadership established different strategies. We needed to find athletes and coaches in different provinces. One way was writing the WC manual to share with coaches across the country. Another strategy was to invite coach developers to work with provincial teams because they have sound curling and sport sciences knowledge. In a sense, the only additional knowledge they would need would be the "para" side of the sport. Also, I've been traveling across the country to deliver WC training camps for the NTP athletes since 2004! Plus, I went to all of the Paralympics and World Championships. Because WC is still in its infancy, we cannot settle and I'm constantly seeking innovations and connecting with researchers from different parts of the country to design tools and support the NTP.

\section{R1: That's great. Is there a difference between coaching wheelchair and able-bodied curling?}

Travis: Coaching is coaching. It doesn't matter if it's an ablebodied team or a WC team. In both teams you'll coach each individual's abilities, you understand what their gaps and strengths are, and work to optimize what they do well and minimize the impact of what they are still struggling with. Of course, my mindset evolved over the last 15 years. When I started, I didn't know where to go to answer all of the questions I had, so I tinkered a lot. You also need to dedicate a good amount of time to knowing each athlete and what is happening with them at different levels, from their relationships with family, with colleagues at work, with teammates, and so on. The biggest difference is that when coaching athletes with a disability, you'll add a few other people who might be important to them such as a physio or another care provider, and the most important person to inform your coaching is the athlete.

\section{R1: Are there any benefits that you have gained from partici- pating in the PLG?}

Travis: Absolutely. I think having access to developmental coaches is a big benefit since they might be the ones identifying the next Paralympians. We understand that their job is lonely in many ways, so if we can continue doing what we have done, which is facilitating training camps, selecting the national team, and so on; and doing it over the Internet, we can reach a larger audience; which is fantastic. One of the biggest challenges of having a selection of players from across the country is that everybody has to be on the same page. Since the NTP athletes are from different provinces, it is important that their home coaches are aware and speaking the same language as the NTP; this way we can be consistent with the delivery of drills and athlete preparation to perform on demand. While we have always had this open-door policy, not many coaches reach out to us. The PLG provided a platform upon which the coaches felt comfortable posing questions and being assured that we were there to listen to them. And this also keeps us accountable. The coaches are not only ones who benefitted from the PLG, we all did.

Value created for coaches at the top of the HP hill. The five dimensions of learning values for coaches at the top of the HP hill encompassed (a) generational encounters (immediate), (b) potential collaborators (potential), (c) leveraged connections (applied), (d) organizational (realized), and (e) institutional change (transformative). Until now, the coaches depicted by the previous vignettes had mentioned their aspirations to access the NTP coaches and resources provided by Curling Canada. Travis' vignette was inspired by the NTP coaches and some coach developers, who were the influential people for the coach participants. The values created for Travis through his participation in the PLG were related to increasing alignment. Travis reported value in the dimensions of generational encounters and potential collaborators when he made reference to the benefit of interacting with recreational coaches who may find the next athlete to be fast tracked to the NTP, a relatively common pathway for Paralympians (Bundon, 
Ashfield, Smith, \& Goosey-Tolfrey, 2018). Moreover, the alignment sought by Curling Canada technical leaders pointed to the importance of leveraging connections. This dimension was the platform upon which the coaches were able to access the NTP program and come to understand the language, drills, and techniques used to develop their athletes in line with the national criteria. The coaches' access to knowledge shared by the NTP resulted in value at the organizational level. Curling Canada's (2019) mission statement reads: "to encourage and facilitate the development and growth of curling." Finally, the institutional change dimension is apparent through the PLG that allowed Travis to communicate with coaches from across the country without having to wait for the competitions or training camps where he typically would meet only a few of the coaches from the HP hill. This institutional change led to greater interaction between the recreational and the HP hills, as symbolized by the bridge in Figure 1.

\section{Increasing the Learning Capability}

As indicated above, the PLG led to numerous dimensions of value for the participants through the increase of the learning capability. The social learning space intervention identified many gaps within the WC landscape. We made use of the analogy of a bridge to support the idea of increasing the flow of communication between coaches of the different hills. In our earlier work, Duarte et al. (2020b) found a "rope bridge" serving the purpose of connecting a very few recreational and middle of the HP hill coaches to the top of the HP hill. An important feature of the WC landscape, as well as other parasport landscapes, is the virtual absence of a developmental hill, which accounts for the necessity to build the capacity and utility of this bridge. By leveraging the access to the HP hill for all coaches regardless of their residency within the landscape, the learning capability of the organization was nurtured. The PLG developed many learning activities to provide all participants with access to knowledgeable people, and this arose in a few ways. First, the flow of information from the HP hill allowed a greater alignment between HP coaches and recreational ones concerning athlete performance. Second, the flow from the recreational to the HP hill provided access to different perspectives and potential collaborations. Moreover, the availability of the top of the hill coaches redefined the way recreational coaches viewed the NTP.

The four vignettes presented how the coaches perceived the PLG. First, the incomers and recreational hill coaches greatly benefitted from the resources shared by the coaches in the middle and at the top of the HP hill. This increased access to more advanced peers is recognized as a major aspect of CoPs that facilitates newcomers' learning of the subculture, language, and shared repertoire of a group (Culver \& Trudel, 2006; Wenger, 1998). Furthermore, since the recreational hill affords very few practice and competitive occasions, the learning opportunities are very limited for acquiring knowledge in action (Schön, 1983). The PLG substantially increased the use of the bridge, producing ample examples of immediate and potential values. For coaches on the HP hill, the PLG did not greatly increase their access to peers since they compete often, but the PLG facilitated their access to different perspectives in a convenient way through the use of online tools. The PLG indeed facilitated the work of Travis, as he could reach coaches across the country without traveling. Previous work in coach development found that coaches of various competencies and experiences all benefited from their participation in a CoP (Culver \& Trudel, 2006). Overall, in relation to reflective practice for coach development, coaches' reflective conversation is facilitated by the access to others (Gilbert \& Trudel, 2001).

\section{Reflections and Recommendations}

Instead of a narrow focus on the value created for parasport coaches through this social learning intervention, an overall discussion of the use of the VCF to consider coach development in this social learning space has been considered. Previous explorations of social learning spaces have reported such outcomes as increased reflection (e.g., Garner \& Hill, 2017) and augmented interpersonal and intrapersonal knowledge (e.g., Araya et al., 2015). The VCF, coupled with learning theories such as those of Jarvis (2009) and Moon (2001), allow us to understand learning and the process of possible or eventual changes to practice through another lens. In addition, the cross analysis of the four vignettes permits us to make several observations about learning. Specifically, those who wish to provide coach development opportunities should consider that learning is not only comprised of behavioral change. Rather, learning must be understood as the cognitive, emotive, and practical transformations that change a person when these transformations are integrated into their cognitive structure/biography (Jarvis, 2009; Moon, 2001; Trudel, Culver, \& Werthner, 2013). With this in mind, coach developers need to be creative in the ways they design learning activities such that coaches experience learning in all its forms. Table 2 demonstrates the links between the VCF value cycles, their dimensions, and different elements of learning (cognitive, emotive, and/or practical). Coach developers can use these examples to frame learning activities that have been shown to be appreciated by coaches.

Likewise, those charged with assessing coach learning should also consider the various value dimensions and design assessments that capture learning that might not be immediately evident in behavior change. For incomers and recreational coaches, immediate value was largely demonstrated emotively. Since these coaches did not attend many competitions, they experienced excitement and a sense of inclusion that resulted directly in personal level realized value. This is an interesting reflection of how learning value can move from one value cycle to another, skipping the ones in between (immediate to realized). The entanglement of the three elements of learning can be a challenge. For instance, the resources dimension could easily be viewed as cognitive. However, the example of the incomer coach illustrated that despite a lack of material produced for parasport coaches (Tawse, Bloom, Sabiston, \& Reid 2012), the large amount of information cocreated by the social learning space led the incomer coach to feel, at least initially, overwhelmed emotionally. However, the support of the social learning space over time, including ongoing access to the resources on Basecamp, provided the incomer coach with the time required to move beyond this emotive reaction to a place where she could start to understand (cognitive) and use (practical) the resources.

More generally, this paper contributes to the literature of sport coaching in a few ways. First, we utilized the VCF (Wenger et al., 2011; Wenger-Trayner \& Wenger-Trayner, 2020) to assess the value created through the involvement of the coaches in different types of learning activities, including online group meetings, online camps, and forums, over a 13-month period. Second, we analyzed the data based on the context in which coaches were involved with the sport (i.e., recreational and HP). Third, we illustrated the latest 
advancements of the social learning theory (Wenger-Trayner \& Wenger-Trayner, 2020), making use of vignettes to provide naturalistic generalizations (Sparkes \& Smith, 2013) for both coaches and coach developers willing to transfer theory to practice. While immediate, potential, and applied values were the prevalent values found in previous studies that made use of the VCF to investigate coaches' CoPs (e.g., Bertram et al., 2016, 2017) and landscapes of practice (Vinson et al., 2019), the four vignettes additionally presented examples of realized and transformative values. It is likely that the longitudinal nature of the intervention contributed to this, as these latter learning values take time to arise (Wenger et al., 2011). Similar to earlier studies that indicated timing is important for actual changes in practice to occur (Bertram et al., 2017; Leduc, Culver, \& Werthner, 2013), the first online group meeting and online camps occurred from May to September, when the majority of the coaches were not coaching because of the sport season (summer in Canada). Thus, the coaches were exposed to content but did not have the opportunity to apply the new knowledge right away, then report back to the PLG. Practically, this implies that coach assessments should occur over time and not just immediately following coach learning activities.

The social learning space participants, the coaches, the Curling Canada technical leaders, and the researchers were highly involved in the intervention. Such ideal conditions may be rare. Therefore, future social learning initiatives will need to emphasize the importance of the systems convener working diligently and deliberately to lay the groundwork through strategic conversations (see Duarte et al., 2020a). Finally, these findings should provide naturalistic generalizations to guide the exploration of other unique landscapes. Future research could implement a social learning intervention including other stakeholders within landscapes, such as athletes. Also, studies could look at the longitudinal value of nurturing social learning spaces-in particular, if participation in a social learning space might facilitate coaches moving from one hill in a sport landscape to another.

\section{Conclusion}

Readers should bear in mind that this paper is the third in a series of articles using collaborative inquiry. The first article mapped the WC landscape (Duarte et al., 2020b). This led to the second article, which delved into the framing of the social learning intervention, guided by the main considerations of the mapping article (Duarte et al., 2020a). That is, together, we created an intervention to provide the participant coaches with meaningful learning activities by making use of the synergies already in the landscape, like training camps and competitions, to increase the interactions between the Curling Canada technical leaders and the participant coaches. The present paper illustrated different types of value created during the intervention that aimed to increase the learning capability of Canadian WC coaches using the VCF and a landscape of practice perspective. Each of the four vignettes presented five dimensions of learning value, one for each of the immediate, potential, applied, realized, and transformative value cycles. The composite vignettes tell the stories of the learning values created for individual coaches in relation to their location in the landscape. The sixth value cycle, orienting, was experienced as the coaches gained a greater understanding of each other's histories and contexts. Collectively, this series of articles provides sport organizations with a blueprint that has the potential to inspire their efforts to maintain an ongoing coach development initiative.

\section{Acknowledgments}

This research was funded by the Social Sciences and Humanities Research Council of Canada, an Ontario Graduate Scholarship, and the Sport Canada Research Initiative.

\section{Note}

1. The term intervention used here is synonymous with initiative. Intervention here denotes jointly nurturing a social learning space as a collaborative inquiry.

\section{Author Biographies}

Dr. Tiago Duarte is a post-doctoral fellow at the University of Ottawa and has worked as a social learning leader with sport organizations since 2016. His main interests include coach development, sport psychology, and parasport.

Dr. Diane Culver is an Associate Professor in the School of Human Kinetics, University of Ottawa. Her research examines coach development, women leaders in sport, and qualitative research. In her teaching, research, and consulting, Diane is particularly interested in social learning theory and building social learning capability in groups and organizations.

Dr. Kyle Paquette is a certified mental performance consultant and professor at the University of Ottawa. He specializes in optimizing learning, performance, and culture in high-performance sport. He works as the Mental Performance Lead for Curling Canada.

\section{References}

Araya, J., Bennie, A., \& O’Connor, D. (2015). Understanding performance coach development: Perceptions about a postgraduate coach education program. International Sport Coaching Journal, 2(1), 3-14. doi:10.1123/iscj.2013-0036

Bertram, R., Culver, D.M., \& Gilbert, W. (2016). Creating value in a sport coach community of practice: A collaborative inquiry. International Sport Coaching Journal, 3(1), 2-16. doi:10.1123/iscj.2014-0122

Bertram, R., Culver, D.M., \& Gilbert, W. (2017). A university sport coach community of practice: Using a value creation framework to explore learning and social interactions. International Journal of Sports Science \& Coaching, 12(3), 287-302. doi:10.1177/ 1747954117710503

Braun, V., Clarke, V., \& Weate, P. (2016). Using thematic analysis in sport and exercise research. In B. Smith\& C. Sparkes (Eds.), Routledge handbook of qualitative research in sport and exercise (pp. 191-205). Oxon, UK: Routledge.

Bray, J., Lee, J., Smith, L., \& Yorks, L. (2000). Collaborative inquiry in practice: Action, reflection, and making meaning. Thousand Oaks, CA: SAGE.

Bundon, A., Ashfield, A., Smith, B., \& Goosey-Tolfrey, V.L. (2018). Struggling to stay and struggling to leave: Experiences of elite paraathletes at the end of their sport careers. Psychology of Sport and Exercise, 37, 296-305. doi:10.1016/j.psychsport.2018.04.007

Burke, S. (2016). Rethinking 'validity' and 'trustworthiness' in qualitative inquiry. In B. Smith\& C. Sparkes (Eds.), Routledge handbook of qualitative research in sport and exercise (pp. 330-339). Oxon, UK: Routledge.

Callary, B. (2013). Coaches create and sustain a community of practice. Phenex Journal, 4(3), 1-13.

Cassidy, T., \& Rossi, T. (2006). Situating learning: (Re)examining the notion of apprenticeship in coach education. International Journal of 
Sports Science \& Coaching, 1(3), 235-246. doi:10.1260/17479540 6778604591

Cregan, K., Bloom, G.A., \& Reid, G. (2007). Career evolution and knowledge of elite coaches of swimmers with a physical disability. Research Quarterly for Exercise and Sport, 78(4), 339-350. PubMed ID: 17941538 doi:10.1080/02701367.2007.10599431

Culver, D., \& Trudel, P. (2006). Cultivating coaches' communities of practice: Developing the potential for learning through interactions. In R. Jones (Ed.), The sport coach as educator: Reconceptualising sport coaching (pp. 97-112). London, UK: Routledge.

Culver, D.M., Trudel, P., \& Werthner, P. (2009). A sport leader's attempt to foster a community of practice. International Journal of Sports Science \& Coaching, 4(3), 365-383. doi:10.1260/174795409789623900

Culver, D.M., Werthner, P., \& Trudel, P. (2019). Coach developers as 'facilitators of learning' in a large-scale coach education programme: One actor in a complex system. International Sport Coaching Journal, 6(3), 296-306.

Curling Canada. (2019). What we do, our mandate and mission. Retrieved from https://www.curling.ca/about-curling-canada/what-we-do/ourmandate-and-mission/

Cushion, C. (2008). Clarifying the concept of communities of practice in sport: A commentary. International Journal of Sports Science \& Coaching, 3, 15-17.

Deal, C.J., \& Camiré, M. (2016). University student-athletes' experiences of facilitators and barriers to contribution: A narrative account. The Qualitative Report, 21(11), 2087-2102.

Denison, J. (1996). Sport narratives. Qualitative Inquiry, 2, 351-362.

Duarte, T., \& Culver, D. (2014). Becoming a coach in developmental adaptive sailing: A lifelong learning perspective. Journal of Applied Sport Psychology, 26(4), 441-456. PubMed ID: 25210408 doi:10. 1080/10413200.2014.920935

Duarte, T., Culver, D., \& Paquette, K. (2020a). Framing a social learning space for wheelchair curling. International Sport Coaching Journal, 1(aop), 1-13. doi:10.1123/iscj.2019-0095

Duarte, T., Culver, D., \& Paquette, K. (2020b). Mapping Canadian wheelchair curling coaches' development: A landscape metaphor for a systems approach. International Sport Coaching Journal. Advance online publication. doi:doi:10.1123/iscj.2018-0099

Ely, M., Vinz, R., Downing, M., \& Anzul, M. (1997). On writing qualitative research: Living by words. New York, NY: Routledge.

Erickson, K., Côté, J., \& Fraser-Thomas, J. (2007). Sport experiences, milestones, and educational activities associated with highperformance coaches' development. The Sport Psychologist, 21(3), 302-316. doi:10.1123/tsp.21.3.302

Garner, P., \& Hill, D.M. (2017). Cultivating a community of practice to enable coach development in Alpine ski coaches. International Sport Coaching Journal, 4(1), 63-75. doi:10.1123/iscj.2016-0076

Gilbert, W., \& Trudel, P. (2001). Learning to coach through experience: Reflection in model youth sport coaches. Journal of Teaching in Physical Education, 21(1), 16-34. doi:10.1123/jtpe.21.1.16

Heron, J. (1996). Co-operative inquiry: Research into the human condition. London, UK: SAGE.

Jarvis, P. (2009). Learning to be a person in society. New York, NY: Routledge.

Jones, R., Morgan, K., \& Harris, K. (2012). Developing coaching pedagogy: Seeking a better integration of theory and practice. Sport, Education and Society, 17(3), 313-329. doi:10.1080/13573322. 2011.608936

Kohe, G.Z., \& Peters, D.M. (2017). High performance disability sport coaching. New York, NY: Routledge.

Lave, J., \& Wenger, E. (1991). Situated learning: Legitimate peripheral participation. New York, NY: Cambridge University Press.
Leduc, M., Culver, D.M., \& Werthner, S. (2012). Following a coach education programme: Coaches' perceptions and reported actions. Sports Coaching Review, 1(2), 135-150. doi:10.1080/21640629. 2013.79775

McMaster, S., Culver, D., \& Werthner, P. (2012). Coaches of athletes with a physical disability: A look at their learning experiences. Qualitative Research in Sport, Exercise and Health, 4(2), 226-243. doi:10.1080/ 2159676X.2012.686060

Moon, J. (2001). Short courses and workshops: Improving the impact of learning and professional development. London, UK: Kogan Page.

Occhino, J., Mallett, C., \& Rynne, S. (2013). Dynamic social networks in high performance football coaching. Physical Education and Sport Pedagogy, 18(1), 90-102. doi:10.1080/17408989.2011. 631003

Paquette, K., Trudel, P., Duarte, T., \& Cundari, G. (2019). Participating in a learner-centered coach education program: Composite vignettes of coaches' and coach educators' experiences. International Sport Coaching Journal, 6(3), 274-284. doi:10.1123/iscj.20180085

Rynne, S. (2014). 'Fast track' and 'traditional path' coaches: Affordances, agency and social capital. Sport, Education and Society, 19(3), 299_ 313. doi:10.1080/13573322.2012.670113

Schön, D.A. (1983). The reflective practitioner: How professionals think in action. New York, NY: Basic Books.

Sparkes, A.C., \& Smith, B. (2013). Qualitative research methods in sport, exercise and health: From process to product. London, UK: Routledge.

Stoszkowski, J., \& Collins, D. (2012). Communities of practice, social learning and networks: Exploiting the social side of coach development. Sport, Education and Society, 19(6), 773-788. doi:10.1080/ 13573322.2012.692671

Stoszkowski, J., \& Collins, D. (2017). Using shared online blogs to structure and support informal coach learning. Part 1: A tool to promote reflection and communities of practice. Sport, Education and Society, 22(2), 247-270. doi:10.1080/13573322.2015. 1019447

Stoszkowski, J., Collins, D., \& Olsson, C. (2017). Using shared online blogs to structure and support informal coach learning. Part 2: The participants' view and implications for coach education. Sport, Education and Society, 22(3), 407-425. doi:10.1080/13573322. 2015.1030382

Tawse H., Bloom, G.A., Sabiston, C.M., \& Reid, G. (2012). The role of coaches of wheelchair rugby in the development of athletes with a spinal cord injury. Qualitative Research in Sport, Exercise and Health, 4(2), 206-225. doi:10.1080/2159676X.2012.685104

Taylor, S., Werthner, P., \& Culver, D.M. (2015). Dynamic, evolving, and social: The learning interactions of parasport coaches. In P. Davis (Ed.), The psychology of effective coaching and management. Nova Hauppauge, NY: Nova Science.

Trudel, P., Culver, D., \& Werthner, P. (2013). Looking at coach development from the coach-learner's perspective: Considerations for coach development administrators. In P. Potrac, W. Gilbert, \& J. Denison (Eds.), Routledge handbook of sports coaching (pp. 375-387). London, UK: Routledge.

Trudel, P., \& Gilbert, W. (2013). The role of deliberate practice in becoming an expert coach: Part 3-Creating optimal settings. Olympic Coach Magazine, 24(2), 15-28.

Vinson, D., Cale, A., Lasota, P., Huckle, V., Faulkner, C., \& Jones, G. (2019). Chapter nine: Investigating the value created through a selective talent and performance coach development programme. In C.L.T. Corsby\& C.N. Edwards (Eds.), Exploring research in 
sports coaching and pedagogy: Context and contingency (pp. 73-83). Newcastle, UK. Cambridge Scholars Publishing.

Wenger, E. (1998). Communities of practice: Learning meaning and identity. New York, NY: Cambridge.

Wenger, E., McDermott, R.A., \& Snyder, W. (2002). Cultivating communities of practice: A guide to managing knowledge. Boston, MA: Harvard Business School Press.

Wenger, E., Trayner, B., \& De Laat, M. (2011). Promoting and assessing value creation in communities and networks: A conceptual framework. Report 18. Ruud de Moor Centrum, Open University of the Netherlands, Heerlen, The Netherlands.

Wenger-Trayner, B., Wenger-Trayner, E., Cameron, J., Eryigit-Madzwamuse, S., \& Hart, A. (2017). Boundaries and boundary objects: An evaluation framework for mixed methods research. Journal of Mixed Methods Research, 13(3), 321-338. doi:10.1177/15586898177 32225
Wenger-Trayner, E., \& Wenger-Trayner, B. (2015). Learning in a landscape of practice: A framework. In E. Wenger-Trayner, M. Fenton-O'Creevy, S. Hutchinson, C. Kubiak, \& B. Wenger-Trayner (Eds.), Learning in landscapes of practice: Boundaries, identity, and knowledgeability in practice-based learning (pp. 13-29). New York, NY: Routledge.

Wenger-Trayner, E., \& Wenger-Trayner, B. (2020). Learning to make a difference: Value creation in social learning spaces. New York, NY: Cambridge University Press.

Williamson, G.R., \& Prosser, S. (2002). Action research: Politics, ethics and participation. Journal of Advanced Nursing, 40(5), 587-593. PubMed ID: 12437608 doi:10.1046/j.1365-2648. 2002.02416.x

Winchester, G., Culver, D., \& Camiré, M. (2011). The learning profiles of high school teacher-coaches. Canadian Journal of Education, 34, 216-233. 


\section{Appendix: Vignette Construction}

We deliberately selected excerpts from all participants and all data techniques. Below, we only provide the first couple of paragraphs; however, all the references for this entire vignette are included below.

\section{Nancy, the Incomer: “I Don't Know What I Don't Know!”}

R1: Tell me a little bit about your curling experience. ${ }^{1}$

Nancy: I got involved with wheelchair curling due to my own impairment. I tried many different sports like wheelchair basketball, ${ }^{2}$ but at my age (50s), the stamina isn't there anymore. ${ }^{3}$ A "wheelie" friend of mine kept bugging me to join the team because it is always a struggle to find wheelchair users who want to stay seated inside the freezer [laughs], I mean on the ice sheet. ${ }^{4}$ So, I showed up and had so much fun! I was hooked by the sense of community! ${ }^{5}$ Locally, we always played against $\mathrm{AB}$ teams because there aren't any other local wheelchair teams; well, not even adapted clubs. ${ }^{6}$ Since they needed a fourth player to compete regionally, although I was Nancy the newbie curler, I travelled to a few tournaments within five hours from home. How bizarre that one week we played against $A B$ teams in our recreational league at the club, and the next we competed against nations that were at the Paralympic Games! And sometimes, we even beat them! $!^{7}$

$\mathrm{R} 1$ : Yes, that is bizarre! What else about competitions was remarkable? ${ }^{8}$

Nancy: Well, at the provincial championships we only played one team. ${ }^{9}$ At the nationals, Curling Canada requires that every team brings a coach, which means that a few provinces only work with coaches for a week over the year. ${ }^{10}$ Actually, the difficulty of finding a coach to work with us is what motivated me to become a coach. ${ }^{11}$

\section{Notes}

1. The mapping interviews included the question above. The first author paraphrased it during the many interviews.

2. Quote slightly edited from the mapping interview.

3. The age of the WC athletes was observed at many competitions.

4. The quote was paraphrased from the notebook with observations from the event.
5. Quote from mapping interview.

6. Similar quotes from many coaches referred to the lack of competition.

7. After attending three different competitions and observing the disparity of teams competing, from recreational teams to Paralympic teams, I would informally discuss the topic with many of the coaches. Many of their perspectives helped me build the quote above.

8. Fictional question included to provide segue to other particularities of the landscape.

9. Quote provided during an online meeting.

10. Observations at the third competition informally discussed with coaches.

11. Quote from a mapping interview.

12. Quote from the follow-up interview.

13. Quote slightly paraphrased from a mapping interview.

14. Quote paraphrased from the final interview.

15. Fictional quote added to provide segue and add flow for the reader.

16. Quote paraphrased from the final interview.

17. Quote from the follow-up and final interviews.

18. Quote from focus group.

19. Quote slightly changed from the final interview.

20. Quote from a final interview.

21. Probing question from final interview.

22. This anecdote started at the second competition I attended, when a coach-athlete mentioned not approaching other coaches for being afraid of being judged as a spy. The next competition, after a few months I noticed the coach sitting with other coaches. After, the game was over, I engaged in an informal conversation about the episode, which resulted in the excerpt above. The story was slightly paraphrased. 